\title{
THE POSSIBILITIES OF CHOSEN APPLICATIONS OF CONTROL AND NAVIGATION SYSTEMS IN GENERAL AVIATION AIRCRAFT AND UNMANNED AIR VEHICLES
}

\section{J. Gruszecki, A. Tomczyk, B. Dołęga, T. Rogalski, P. Rzucidło}

Rzeszow University of Technology, Department of Avionics and Control, ul. W. Pola 2, 35-959 Rzeszow, Poland E-mail: awionjgr@prz.edu.pl,atomczyk@prz.edu.pl,dolbog@prz.edu.pl,orakl@prz.edu.pl,pawelrz@prz.edu.pl Received 1101 2007, accepted 11062007
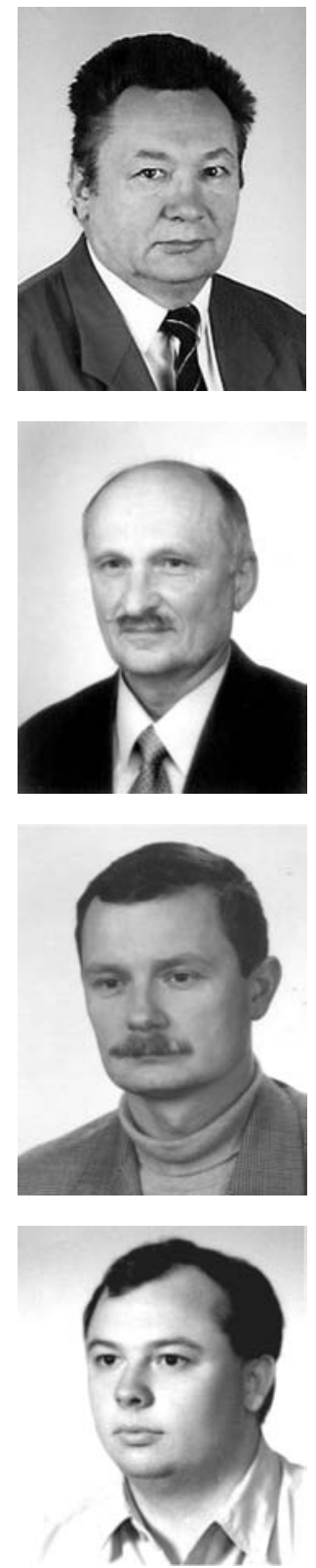

Jan GRUSZECKI, Prof Dr Sc Eng

Date of birth: 1941.

Affiliations and functions: Head of the Department of Avionics and Control at the Faculty of Mechanical Engineering and Aeronautics of Rzeszow University of Technology.

Research interests: The rough set theory, the decision to undertake helping methods, the control system projects at informatics formulation and design.

Experience: Member of the programme working groups of the JEP-12095-97 (as part of the structure requirements and of Syllabuses and Course Study Programmes for avionics specialization consistent with the JAR 66 cat C - Aircraft Control Systems) and the ARTs - Leonardo Programme (as part of the multimedia lectures for pilots and aviation mechanics).

\section{Andrzej TOMCZYK, Dr Sc Eng}

Education: MSc degree in 1970 - Technical University of Warsaw, Faculty of Mechanics and Thermal Engineering. 1976 - Doctorate in technical sciences at the Institute of Fundamental Technical Research of the Polish Academy of Sciences. 2000 - D.Sc. degree at the Military Academy of Technology, Warsaw.

Research interests: Research and design work connected with the synthesis of manual (SAS, CAS), automatic (autopilot) flight control systems, and the Fly-by-Wire control system for executive airplanes.

Experience: Member of the American Institute of Aeronautics and Astronautics since 2001.

Publications: over ninety papers published in scientific journals and conference proceedings, author of two books, coauthor of three patents in the area of aeronautics.

\section{Boguslaw DOŁEGA, PhD Eng}

Date and place of birth: 1962 in Jaslo, Poland.

Education: Rzeszow University of Technology, MSc.

Affiliations and functions: Rzeszow University of Technology, assistant; 1994 - PhD degree from the Department of Mechanical Engineering of Rzeszow University of Technology; since 1995 - Professor Assistant in the Avionics and Control Systems Department at said University.

Research interests: Diagnostic aircraft navigation and control systems, with a focus on the development of the control theory for online fault detection and localization methods.

Experience: Co-organizer of Avionics Conferences.

Publications: Over 40 scientific articles.

Present position: Professor Assistant in the Avionics and Control Systems Department.

Tomasz ROGALSKI, PhD Eng

Date and place of birth: 1972 in Tarnow, Poland.

Education: 1996 - Rzeszow University of Technology, MSc.

Affiliations and functions: 1996 - present -Aviation Department of Reshow University of Technology.

Research interests: Pilot friendly control system for small transportation plane.

Publications: About 30 articles. 


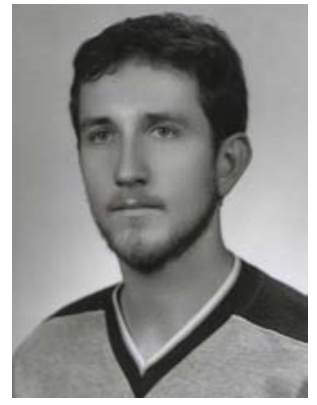

Pawel RZUCIDŁO, PhD Eng

Education: M.Sc. (Eng.) degree in Aeronautics, Rzeszow University of Technology, Faculty of Mechanical Engineering and Aeronautics.

2001 to 2005 - PhD. studies, Rzeszow University of Technology, Faculty of Mechanical Engineering and Aeronautics, Specialization: Machine Building and Exploitation.

2005 to present - Researcher, Rzeszow University of Technology, Department of Avionics and Control. Research interest: Aircraft Control with an Emphasis on Interactions Between Human and Machine.

Publications: Author of four scientific articles and co-author of 12 conference papers.

Abstract. The development of informatics and sensor techniques has extended the possibilities of flight parameter measurement. It allows for extensive modification of control and navigation systems in air vehicles. This advance can also be noticed in the research of the Department of Avionics and Control at the Faculty of Mechanical Engineering and Aeronautics, Rzeszow University of Technology. Research in the area of digital flight control systems was initiated at the Department of Avionics and Control over twenty years ago.

One of the first research works in this field was a digital autopilot for general aviation aircraft M-20 Mewa (APC-1P). At the end of the 90's the control and navigation system for unmanned aircraft (APC-4) was designed and applied on the board of PZL-110 Koliber aircraft. The next step in control system development was the indirect (Fly-by-Wire) flight control system for general aviation aircraft (SPS-1A) [12]. This system was also installed and tested on the board of PZL-110 Koliber aircraft. The solutions mentioned were featured using a new design approach. Available in-market components were chosen in respect of quality and safety. At the same time the improvement of structures of control and navigation systems were worked out. Safety provision was obtained by the use of structures with reconfiguration, induced by the methods of fault detection and localization. These structures are only known in transport or military aircraft.

The progress of theoretical methods of the control systems design was strictly connected with development of production technology. The use of milling and thermo-transfer technology for the manufacture of printed circuits and advanced techniques of electronic devices integration has allowed the development of repeatable methods for manufacturing highly reliable systems. With tens of years of experience in the Department of Avionics and Control, Rzeszow University of Technology contains a lot of conclusions and notices. The authors are going to share some of them in this article.

Keywords: flight control systems, Fly-By-Wire, general aviation, UAV.

\section{Introduction}

The subject matter of this paper is multidisciplinary and it is very hard to present it in one monothematic block. Control systems for general aviation aircraft and unmanned air vehicles have been developed for many years and it is not easy to compare particular solutions. We can discuss design philosophy, applied technologies and methodologies of laboratory and in-flight tests in general. The authors of this paper have had experience in many research and industrial projects (Fig 1-2). They have decided to describe some of the problems noticed during the realization of projects to help avoid them in future solutions. These problems are referred to as:

- structure of navigation and control systems,

- computation and control algorithms,

- components of systems,

- software and hardware diagnostic tools and methods,

- manufacturing and rapid prototyping technologies,

- laboratory and in-flight tests.

The reader can find an extensive explanation of this subject matter in reports and documentation [2, 11]. The Polish State Committee for Scientific Research financed these works for over 10 years. The results of these projects were prototypes of control and navigation systems for general aviation (GA) aircraft as well as for unmanned air vehicles (UAV) [1, 10].

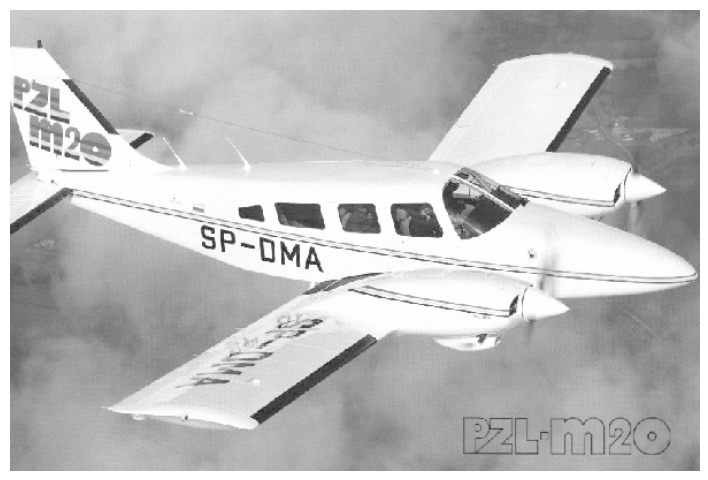

Fig 1. PZL-110 "Mewa" - test platform and demonstrator of digital autopilot APC-1 (1988-1990)

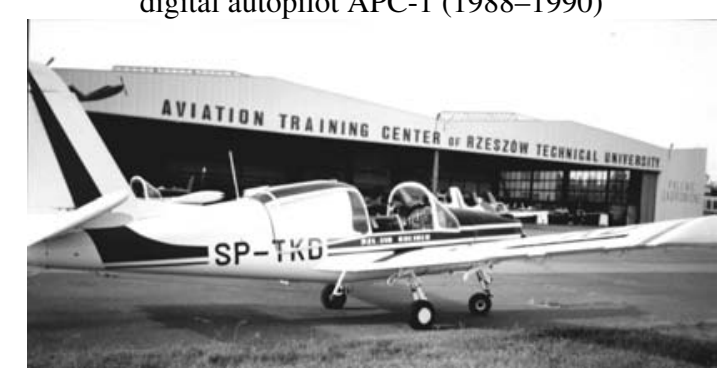

Fig 2. PZL-110 "Koliber" - demonstrator of UAV control and navigation system APC-04 (1996-1999), test platform of SPS-1/A fly-by-wire system for GA (2001-2006) 


\section{Structures of control and navigation systems}

The shape of a system structure depends on many factors. They are opposite in many cases and a compromise is often necessary. Some establishments should be made before selection of a system structure:

- type of controlled object: GA, UAV or other,

- purposes: aero taxi, personal transportation, cargoplane, flying target, spotter, etc.,

- type of propulsion: piston, jet, rocket,

- area of activity (sea, desert, enemy territory),

- data link systems,

- costs of manufacturing and exploitation,

- number of manufactured systems.
Either less or more complicated systems are selected after consideration of the points mentioned above. Two solutions are presented as an example:

- control and navigation system for UAV (flying target),

- control and navigation system for personal transportation aircraft.

The structure of control system for UAV designed for operation in a radius of $25 \mathrm{~km}$ consists of a flight control computer (FCC), an attitude heading reference system (AHRS), an air data computer (ADC), a magnetometer, control surfaces actuators, and a data up/down link for communication with the ground base (Fig 3).

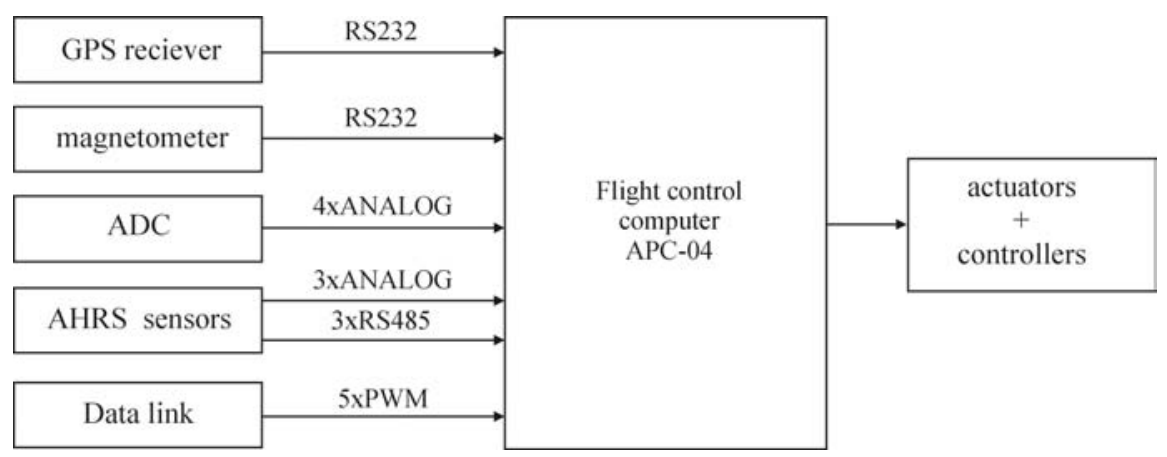

Fig 3. The structure of control and navigation system for an unmanned air vehicle

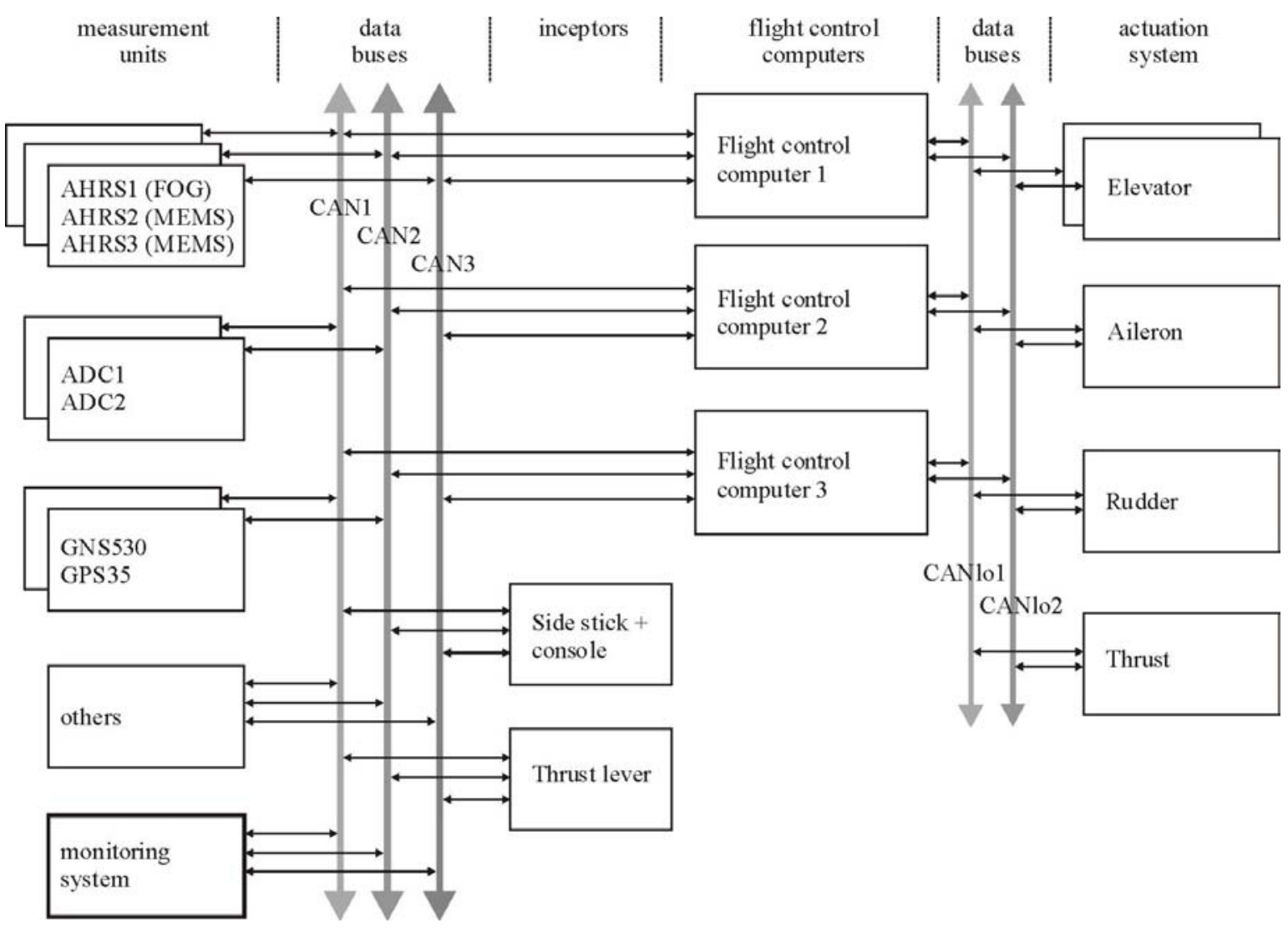

Fig 4. The structure of indirect flight control system for general aviation aircraft 
Particular system devices are connected directly, whereas standard data buses are used in particular cases only. Data buses are single units, and diagnostics systems initialize the "return to base" procedure after localization of any failure. Parachute recovery or self-destruct systems are used in specific circumstances.

The conditions for GA operations are definitely different from that of UAV. The control and navigation systems of these objects are different in effect. The system for GA should perform the following specifications:

- the measurement units accuracy should be close to the accuracies of devices used on boards of large transportation aircraft,

- actuators should ensure the stable work of control surfaces and propulsion systems in the whole flight envelope,

- particular system devices should be continuously monitored, and connected to redundant (doubled, tripled or quadrupled) data buses (MIL, ARINC, CAN - Control Area Network or other).

These two extremely different examples can contain various intermediate solutions. Blocks of AHRS + GPS (Global Positioning System) + filters can be replaced by AHRS only, in the simple flying object UAV. The structure presented in figure 4 can be modified depending on price. Aircraft can be equipped with weather radar, traffic collisions avoidance systems (TCAS), ground proximity warning systems (GPWS), direct lift control systems, and automatic landing systems. Differences in the proposed structures also result from law. Regulations for GA are very detailed in contradistinction to incomplete UAV flight rules.

\section{Control algorithms}

Unmanned air vehicles are controlled autonomously or by an operator located in the ground (or flying) station. Described personal transportation - GA - is also designed for inexperienced pilots. The actions of pilots of small aircraft equipped with indirect flight control systems can be very similar to the actions of UAV operators (omitting motion cues). Time constants for UAV (mass $50-250 \mathrm{~kg}$ ) and GA (mass 1000-3000 kg) are in the range 0.2-2 s. For both classes we can establish:

- synthesis of control laws can be based on linear theory when the total time of one cycle of computations is smaller than $1 / 10$ of the time constant of the object response,

- transfer function of the object (complete with control system) will be adequate to $1 / \mathrm{s}$ (it is comfortable for human behaviour).

Improvement of handling qualities can be achieved by introducing shaping functions in the forward path. Inner control loops can stabilize chosen flight parameters beyond pilot consciousness (figure 5). Authors considered two factors during their assessment of handling qualities: which variables are mostly involved in the pilot-aircraft interaction and what kind of research method allows them to obtain results independent of aircraft dynamics [5].

The structure of the control system is dependent on the state vector of aircraft effective dynamics. Measurement of several flight parameters is impossible in some cases because many GAs are not equipped with advanced measurement units. Missing parameters can be obtained by using state observers (Fig 6) [6].

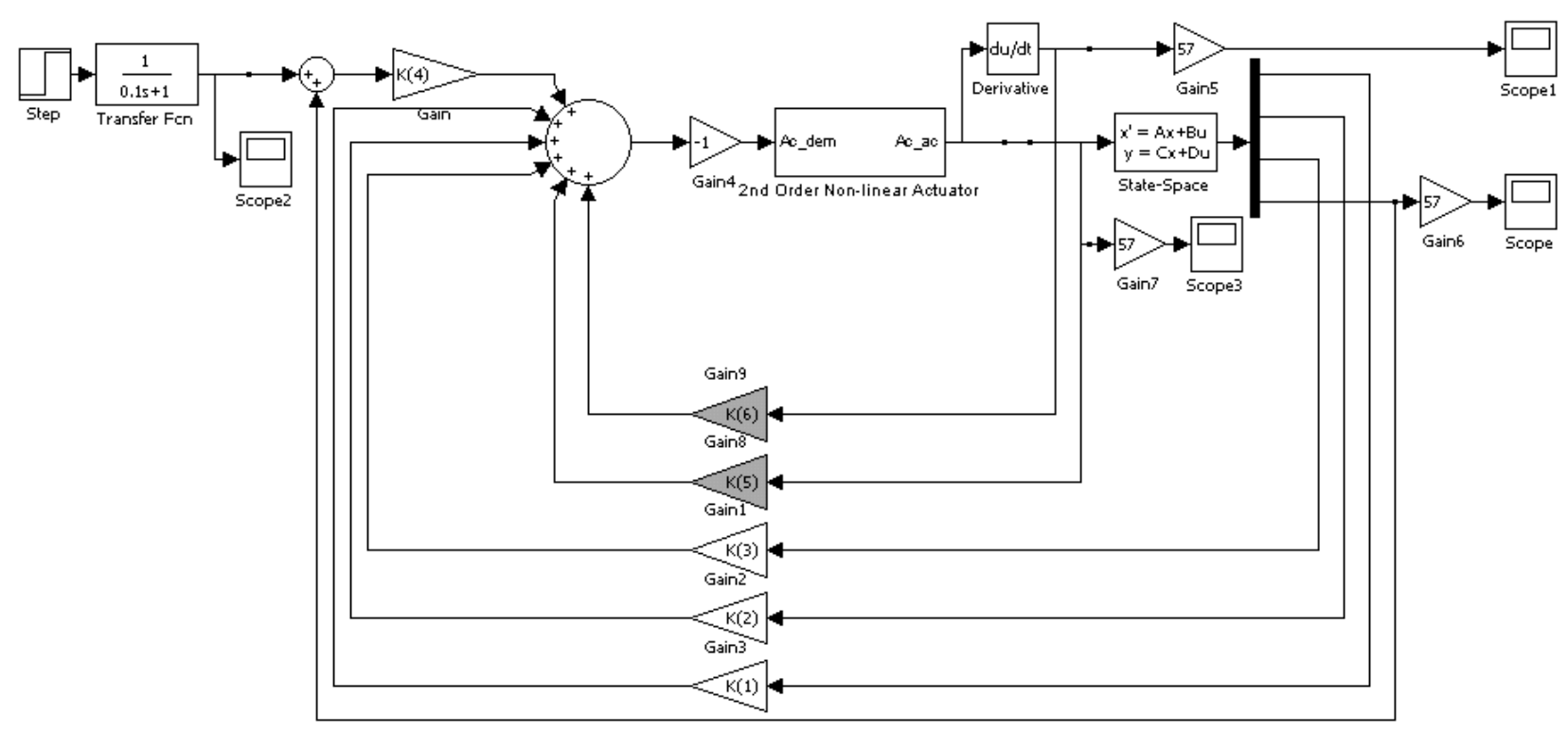

Fig 5. Modified pitch control system 


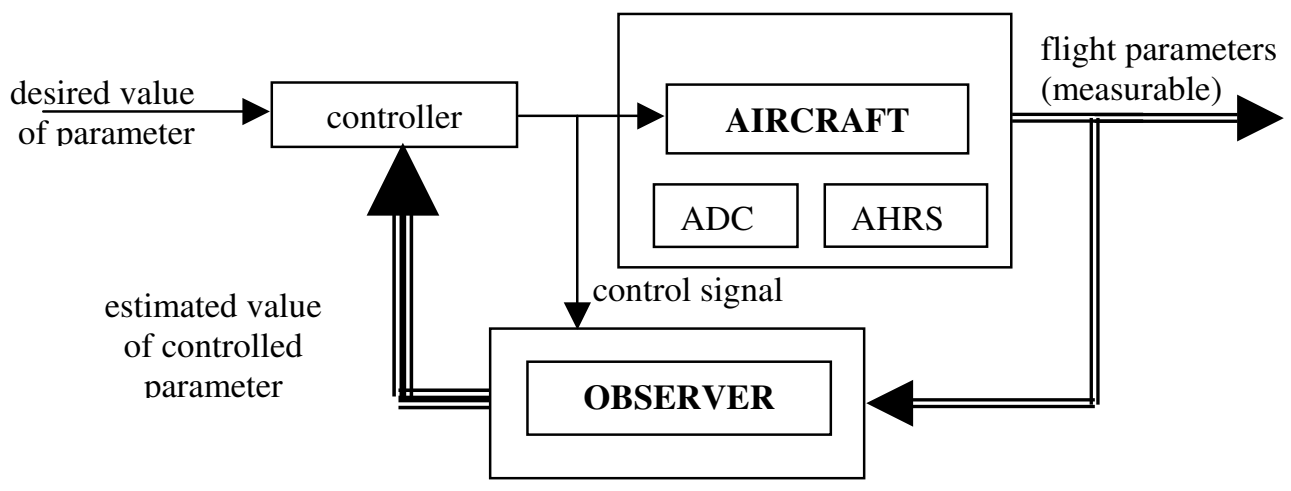

Fig 6. Estimation of values of missing variables

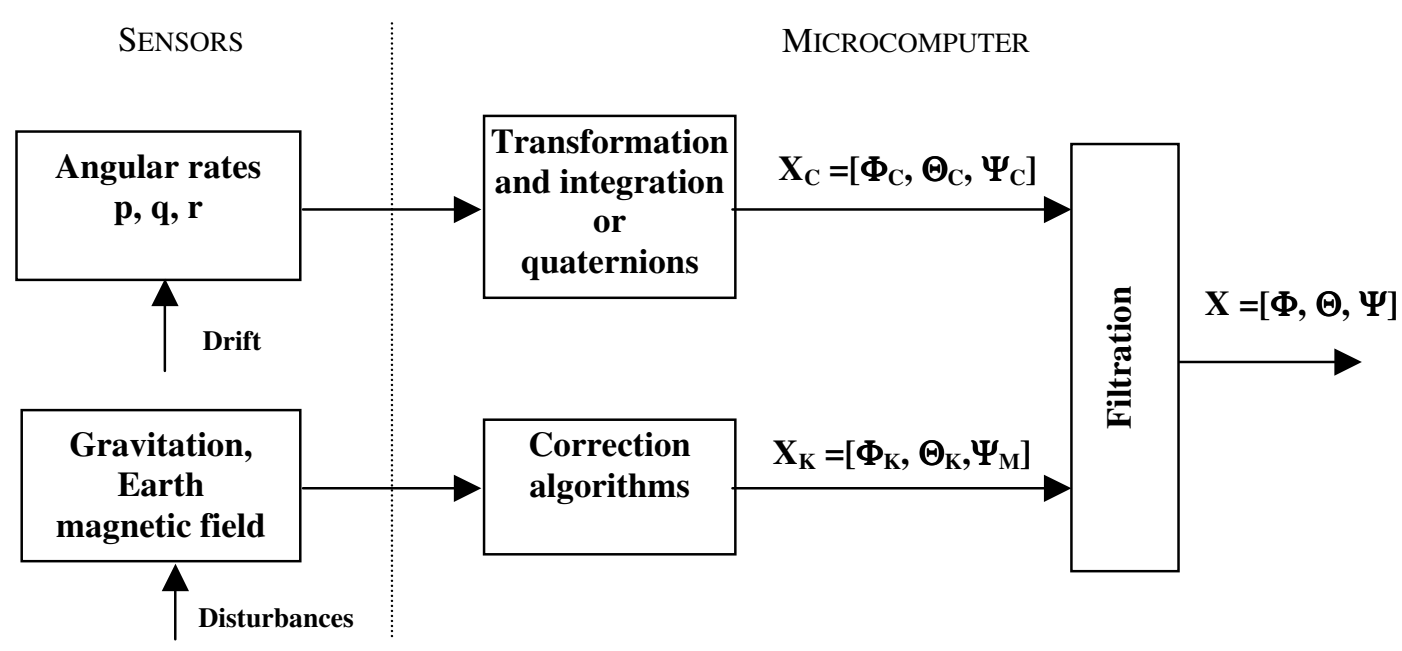

Fig 7. Block scheme of AHRS

The next problem during control law synthesis is consideration of external factors and disturbances, which can have an influence on handling qualities and flight comfort. Not only are atmospheric disturbances important but also aircraft reconfiguration, loading airdrop, asymmetric flow and influence on control quality. Correction blocks should be introduced to control systems for elimination of the mentioned effects. Super or over-sensitivity of inceptors caused by altitude changes can be suppressed by using a shaping function with various gains for deflection of aerodynamic surfaces. Experience shows that the sequence of control laws synthesis should be as follows:

- choosing of state variables for practical realization of control system,

- linear synthesis (methods based on root locus, frequency characteristics or others),

- selection of shaping functions.

Empirical methods are applied in the third stage (off-line and real time simulations).

\section{System components}

The selection of appropriate components for the control and navigation system is very important.
Compromise between quality, price, weight, dimensions and other parameters is necessary in almost every case. Cheap devices can replace expensive high quality components in flying objects (AHRS equipped with micro-electromechanical gyroscopes). Spotters can be equipped with advanced AHRS based on fiber optic gyroscopes. Devices are designed to work together and their compatibility makes the integration process easier. Application of the selected data bus transmission standard determines the choice of adequate devices. Full compatibility between different standards is not possible in many cases. General information regarding the main elements of typical control and navigation systems is listed below.

FCC - structure of flight control computers depends on the structure of the whole control system, data transmission buses (number, standard, capacity), established fault tolerance, and required speed of computations. The structure presented in figure 8 enables the designer easy modification and extension of the control system.

AHRS - strap-down attitude and heading reference system, typical measurements: pitch, roll, yaw angles and rates, accelerations in axes $\mathrm{x}, \mathrm{y}, \mathrm{z}$. A block scheme is presented in figure 7 . 


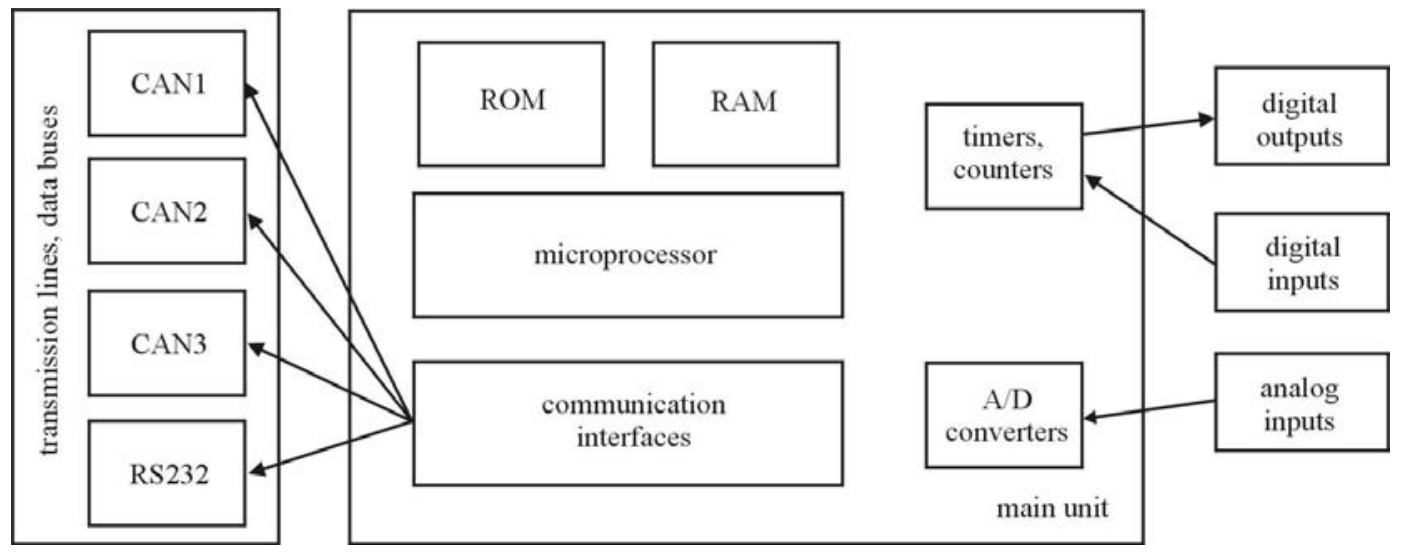

Fig 8. Structure of flight computer [6]

ADC - air data computer, typical measurements: standard pressure (QNH), differential pressure (QFE), speed (CAS, TAS), altitude and climbing rate.

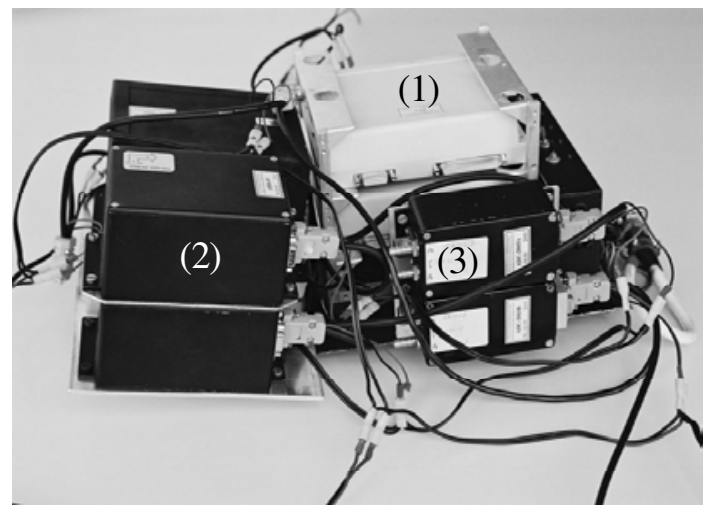

Fig 9. FCCs (1), AHRSs (2) and ADCs (3) as part of flight control system for GA

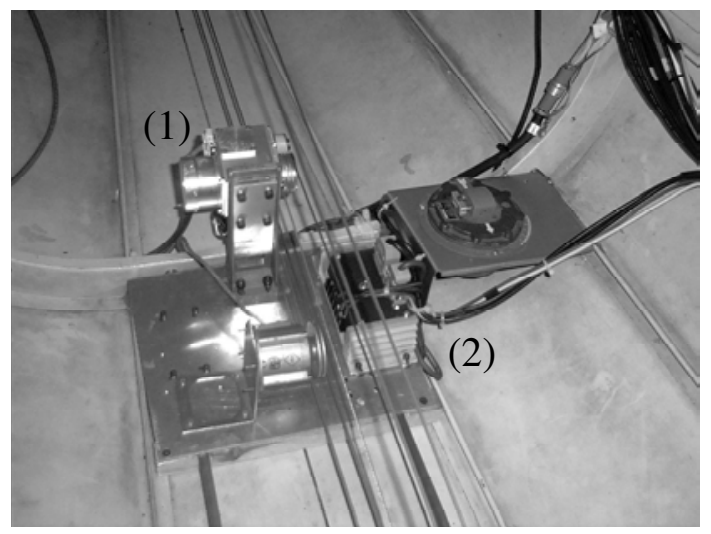

Fig 10. Actuators (1) complete with controllers (2) on the board of experimental PZL-110 aircraft

Navigation modules are responsible for receipt and computation of data from GPS, GNS (Garmin Navigation System), VOR (Very high frequency Omni directional Range) and ILS (Instrumental Landing System). Navigation data are converted and transmitted via data buses to the cockpit and autopilot.

Actuators - hydraulic actuators are fast and powerful but are not appropriate for light objects. Electromechanical actuators, less than $1500 \mathrm{~kg}$ of the aircraft weight, are usually carried. The crossover frequency of the actuator should be over $1 / 5$ of the frequency of short period motion. Modeller actuators are useful for UAVs under 50 $\mathrm{kg}$. Selected actuators should pass the appropriate static and dynamic test programs [9].

\section{Diagnostics}

Interconnections between the hardware and software of the control and navigation system should be taken into consideration before application of chosen diagnostic methods. It can lead to a complex diagnostic system and extended fault detection methods. There are many available diagnostic methods, e.g.:

- direct comparison of the actual state of the system with its faultless model,

- identification of disruptions,

- using decision tables with rough sets analysis,

- usage of the systems with built-in self-test signals.

It is difficult to propose clear rules for the selection of one method from the list mentioned above. The selection depends on many factors:

- structure of the system,

- length of measured-control cycle,

- amount of system test factors,

- performance of the flight control computer,

- required operational reliability,

- established level of redundancy,

- type of flight object,

- predicted mission tasks.

The variability of available diagnostic methods and problems connected with their application makes design tasks of the diagnostic system very specific for the avionics systems [7].

\section{Manufacturing technology}

Electronic equipment installed on the board of the aircraft works in unfavorable conditions. It runs a risk of high frequency and high amplitude mechanical vibrations and oscillations of temperature, humidity, pressure, accelerations, etc. To ensure the proper function of 
electronics, fulfillment of standards described in DO160 and other norms ar required. The design according to norms can lead to a certifying process. The following rules allow obtainment of high quality products:

- particular components and devices should be designed as functional modules,

- avoid hybrid structures (mixed electromechanical, electronic, pneumatic and hydraulic systems),

- apply SMD technology in printed circuits,

- optimize composition of elements on printed circuits in respect of EMI (Electro-Magnetic Interference) and temperature dissipation,

- ensure high power components are fixed directly to circuits and isolated from the base,

- avoid electromechanical relays,

- apply thermo transfer or milling technology for printed circuits.

Computer aided design of printed circuits makes the rapid prototyping and small series manufacturing process easy and certain. Milling or thermo transfer technology enables the manufacturer to reproduce, precise and cheap modules.

\section{Tests}

The building of on-board device simulators is necessary during the early stages of control and navigation system research. During this period a large majority of components are under construction. Simulators allow early and efficient tests of particular devices to be carried out, and enable designers to check interconnections with non-existent hardware [8]. Simulators have facilitated the detection of failures and made laboratory stand tests easier.

During flight tests the possibility of current control of tested devices is necessary [4]. The monitoring system should be responsible for visualization and data recording. It also allows the tuning of particular modules (e.g. setting values of gains in control loops in FCCs), turning on/off the selected device and automatic diagnostics of data buses and modules.

Particular phases of control and navigation tests should be directly connected with design and integration processes. Tests can be divided into four stages:

- computer simulation of control and navigation system algorithms, tuning of parameters, structure corrections,

- laboratory hardware in-the-loop tests,

- tests of functionality of the equipment build on the board of aircraft or UAV, corrections of range of actuators motion, static gains adjusting,

- in-flight tests, verification of the diagnostic system during particular missions, verification of control and navigation systems.

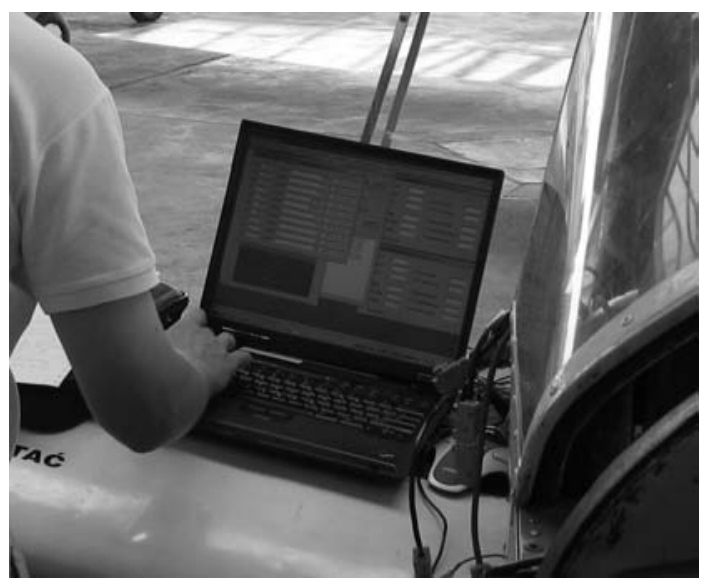

Fig 11. Monitoring system of SPS-1A

The design team realizes the first three phases of tests. Supervision of aviation administration is needed during the fourth stage of tests.

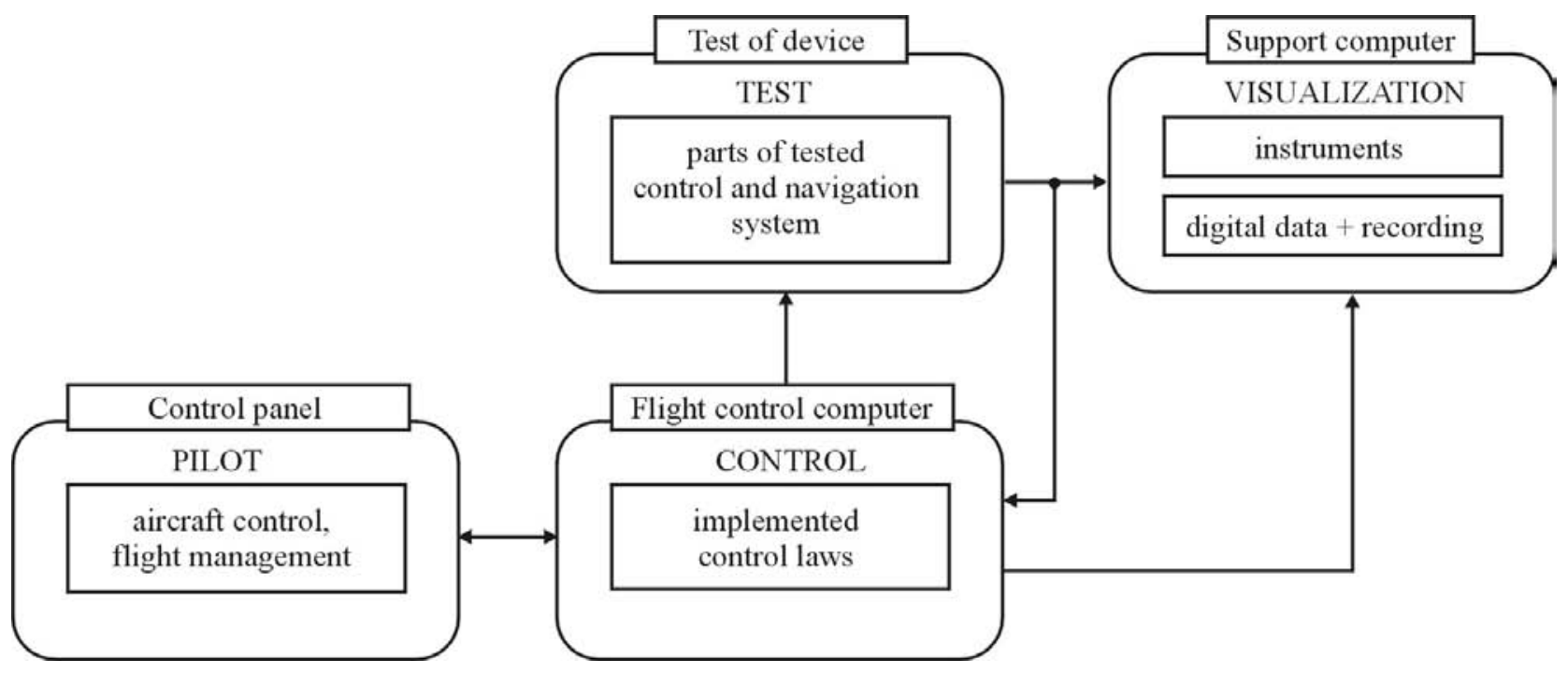

Fig 12. Block scheme of laboratory stand used for complete tests of control and navigation systems 


\section{Conclusions}

The department of Avionics and Control at Rzeszow University of Technology has developed control and navigation systems for GA and UAV for over twenty years. During the past years many new methods and technologies have been introduced into design, manufacturing and test processes.

Computer aided design has improved classical methods considerably and it supports development of control systems with effect from the low-level design of printed circuits to the integration of complex and redundant structures. Electronic components and devices have been miniaturized and their performance has been set up to a high level. Advanced digital technology enables many various interfaces and transmission protocols to be applied, even in low-cost measurement and control units. The use of universal and standardized modules helps to create systems featured by open structure decreases costs of prototypes and reduces labour consumption.

Modern rapid prototyping systems allow the time periods between project and test phases to be shortened. Integrated environments can accelerate the development of control systems, especially with the aid of consolidated multi-level design tools, hardware in-the-loop simulators and multifunctional, portable test platforms.

Comparison of structures of control and navigation systems for GA and UAV shows their solutions are very similar in many areas. The majority of hardware and software components can be used for both platforms in practice. Authors of the paper hope the presented material will be useful and help to avoid some problems during the design of new systems in future.

\section{References}

1. Bezpilotowe aparaty latajace, systemy sterowania i nawigacji (UAV, control and navigation systems). Edited by J. Gruszecki. Rzeszow: Oficyna Wydawnicza Politechniki Rzeszowskiej, 2002.

2. BOCIEK, S., GRUSZECKI, J. Uklady sterowania automatycznego samolotem (Aircraft control systems). Rzeszow: Oficyna Wydawnicza Politechniki Rzeszowskiej, 1999.

3. GRZYBOWSKI, J., RZUCIDŁO, P. Actuators controller for small fly-by-wire aircraft. In International Multidisciplinary Conference. Baja Mare, 2003, p. 193-199.

4. KOPECKI, G., RZUCIDŁO, P. Problems of monitoring in the fly-by-wire system for small aircraft. In AIAA-2006-6340 Paper, AIAA Guidance, Navigation and Control Conference and Exhibit. Keystone, Colorado, 21-24 Aug. 2006.

5. ROGALSKI, T. The conception of the pilot friendly control system for small local communication aircraft. In AIAA 2002-4871. Monterey, California, 2002.
6. ROGALSKI, T. Ksztaltowanie wybranych wlasciwosci eksploatacyjnych samolotow ogolnego przeznaczenia (Shaping of chosen exploitation properties of general aviation aircraft). PhD Thesis. Rzeszow: Rzeszow University of Technology, 2004.

7. ROGALSKI, T., DOŁĘGA, B. The laboratory stand intends to test and prototype control system for small transportation aircraft. In International Multidisciplinary Conference. Baja Mare, 2003, p. 125-131.

8. RZUCIDŁO, P. Monitoring and data acquisition system for experimental general aviation fly-bywire aircraft. Aviation, Vilnius: Technika, 2006, vol. X, no. 3, p. 16-20.

9. RZUCIDŁO, P. Laboratory and preliminary Inflight tests of electromechanical actuators. In SAE Paper2006-01-2414. General Aviation Conference and Exhibition. Wichita, Kansas, 29-31 Aug. 2006.

10. TOMCZYK, A. Facilitated airplane - project and preliminary in-flight experiments. Aerospace Science and Technology. Elsevier, 2004, vol. 8, no. 6, p.469-477.

11. TOMCZYK, A. Poktadowe cyfrowe systemy sterowania samolotem (Digital control systems of aircraft). Rzeszow: Oficyna Wydawnicza Politechniki Rzeszowskiej, 1999.

12. Zintegrowany system pośredniego sterowania lekkim samolotem dyspozycyjnym (Integrated control cystem for general aviation aircraft). Edited by A. Tomczyk. Polish State Committee for Scientific Research 8 T12C 04920. Rzeszów, 2003. 